\title{
Airline Pricing under Different Market Conditions: evidence from European Low-Cost Carriers*
}

\author{
Volodymyr Bilotkach ${ }^{\dagger}$ \\ Newcastle University
}

\author{
Alberto A. Gaggero \\ University of Pavia
}

\author{
Claudio A. Piga ${ }^{\S}$ \\ Keele University \\ RCEA, Rimini, Italy.
}

May 1, 2014

\begin{abstract}
Traditional theories of airline pricing maintain that fares monotonically increase as fewer seats remain available on a flight. This then implies a monotonically increasing temporal profile of fares. In this paper, we exploit the presence of drops in offered fares over time as an indicator of an active yield management intervention by two main European Low-Cost Carriers, and measure its effectiveness. We find that reduction of the offered airfare by one standard deviation raises a flight's load factor on average by 2.7 percent, a measure unaffected by the intensity of competition in a route. Furthermore, yield management interventions are less effective the higher the share of leisure (holiday and visiting friends_relatives) traffic on the route. This result runs counter to the common perception of leisure passengers being more responsive to price changes.
\end{abstract}

JEL Classification: D22, L11, L93.

Keywords: easyJet, Dynamic Pricing, Panel Data, Ryanair, Yield Management.

${ }^{*}$ We are grateful to three anonymous referees for helpful comments, which contributed to ameliorate this paper. We wish to thank Marcus Asplund, Paolo Bertoletti, John Kwoka, Mark Schaffer, participants of the EARIE Conference in Stockholm, the IIOC Conference in Arlington, the RCEA workshop in Rimini, and the seminar participants in Bremen, Pavia and Turin. The responsibility for the arguments and results expressed in this paper is entirely ours.

${ }^{\dagger}$ Newcastle University Business School, 5 Barrack Road, Newcastle upon Tyne, NE1 4SE, United Kingdom. Email: volodymyr.bilotkach@newcastle.ac.uk.

${ }^{\ddagger}$ Department of Economics and Management, Via S. Felice 5, 27100 Pavia, Italy. Email: alberto.gaggero@unipv.it

${ }^{\S}$ Keele Management School, Keele, ST5 5BG, United Kingdom. E-mail: c.piga@keele.ac.uk. Corresponding author. 


\section{Introduction}

Airlines and hotels constitute typical examples of service markets with different mix of business and leisure customers. The emergence of the Internet as a direct marketing channel has had two effects on the travel industry. On the one hand, the Internet has increased firms' market reach, but on the other hand it intensified the competitive pressure and the firms' need to constantly adjust online offered prices to manage their highly perishable capacity. This paper provides a quantitative evaluation of the effectiveness of dynamic pricing interventions, using a unique dataset from the airline industry. Data on final load factors allow us to both quantify the effectiveness of a particular visible form of pricing intervention (decrease in offered price), and examine whether leisure passengers are more responsive than business travelers to price drops. The latter point has clear implications for travel industry managers.

Pricing in the airline industry is known to be very complex, resulting in substantial and well-documented price dispersion. Deneckere and Peck (2012) point out that the airline industry belongs to a rather wide class of markets, where a good is offered for sale for a limited length of time, capacity has to be scheduled in advance, and aggregate demand is uncertain. To cope with these complexities in a competitive environment, airlines have developed and perfected a dynamic capacity pricing approach that allows them to adjust their prices in response to changes in demand. The term commonly used in the airline industry to describe such a pricing approach is yield management (hereafter, YM).

The goal of YM, both systematic and stochastic, is to maximize load factors and profits. Load factor maximization is important due to economies of traffic density (falling per passenger cost with increasing load factor). Under systematic YM, the high- or lowdemand periods can be predicted with sufficiently accurate precision, while stochastic YM entails the management of demand conditions that could not be determined a priori.

Following Dana (1999a), systematic yield management can be effectively related to the practice of setting fares as an ex-ante (non strictly) increasing function of an aircraft's capacity utilization. However, in the event the forecasts turn out to be particularly imprecise and/or unexpected contingencies arise, the need to deal with stochastic YM may induce airlines to revise the pricing schedule they devised under systematic peak load conditions. Stochastic YM and dynamic pricing can thus be seen as synonymous in the sense that they identify changes to a systematic (i.e., defined a priori) pricing schedule. This practice is particularly important when the actual demand is much lower than expected so that, in the absence of any rectifying intervention that shifts at least some fares downward, the aircraft would likely depart with many empty seats.

In this study, we document the effects of dynamic pricing using a unique dataset of offered price profiles of two leading European low cost carriers. Specifically, we observe both the evolution of price quotes for a number of flights as the departure date nears, and the final load factors of those flights. This allows studying the impact of YM interventions observed at various time intervals prior to a flight's departure on the resulting load factors. Our data allow us to observe instances of drops in offered prices as the departure date 
nears, representing clear interventions by the yield managers. We measure the extent to which different levels of price drops are successful in raising a flight's load factor. Surveybased data on the passenger mix on individual routes allow us to evaluate the differences in the magnitude of this effect for predominantly leisure versus predominantly business markets.

The main advantage of our dataset is that the data come from the environment which very closely resembles the one described by various YM models. Specifically, all the tickets in our dataset are offered as strictly non-refundable contracts, irrespective of the price, and the airlines do not practice any discrimination between one-way and round-trip customers. Furthermore, our data allow us to abstract from pricing-in-network considerations, as the carriers involved only sell tickets for point-to-point services. To measure the effectiveness of YM, we employ a flight-level fixed effects model that accounts for the potential endogeneity of the price decrease variable. Econometric estimates reveal that, other things equal, onestandard deviation reduction of the offered airfare results on average in a 2.7 percent higher load factor. For a typical Ryanair 189-seat aircraft, this is equivalent to about 5 extra seats that are sold following this yield management intervention.

Further, we study whether the effectiveness of YM interventions varies across markets with different degrees of either concentration or passenger mix. First, we fail to detect any substantial difference related to a route's concentration, suggesting that price reductions do not appear to lead to passengers substituting between the competing airlines' flights on the route. This finding is largely consistent with the view that the emergence of lowcost carriers in Europe has been a driving force in the expansion of the overall demand for airline services (Alderighi et al., 2012). Furthermore, the effectiveness of yield management interventions decreases with the increase in the share of leisure traffic on the route. This conclusion appears to be counter-intuitive, as leisure passengers are perceived as being price sensitive. A potential explanation for this outcome may be related to the tendency of leisure travelers to make their plans well in advance, which, in turn, enhances the role of systematic YM and makes dynamic pricing less effective.

We must however note two caveats here. First, intertemporal price discrimination is not an alternative hypothesis to our contention, and our finding that YM is practiced effectively does not mean that the airlines do not price discriminate. It is simply that, according to the available information on how airlines set their fares, the temporal price discrimination approach is largely a fixed effect, i.e., a similar temporal template is applied across daily flights operated on the same route sharing the same time of departure. Furthermore, the use of relevant instruments is also designed to purge the yield management variable of possible other time-varying flight-specific effects.

Second, we are aware that YM comprises a wider range of forecasting and pricing practices that we do not study here (Weatherford and Bodily, 1992; McGill and Van Ryzin, 1999) Indeed, we only focus on one particular manifestation, i.e., sustained fare reduction induced by stochastic peak load pricing considerations. Yet, we also control for other more traditional forms of YM such as those discussed in Dana (1999a, 1999b), where the emphasis lies on how fares should be adjusted to reflect systematic peak load pricing 
considerations. Since we only deal with final load factors, we cannot study whether the management of peak load pricing varies with market conditions; addressing this issue will probably require more detailed data on how fares change as a plane fills up (Clark and Vincent, 2012).

The rest of the paper is organized as follows. The relevant literature is presented in the next section; Sections 3, 4, and 5 discuss data, the empirical strategy together our definition of YM intervention, and results, respectively. Section 6 concludes. Some secondary results are in the Appendix.

\section{Literature Review}

This paper makes a contribution to a small but growing empirical literature on application of yield management by the travel industry. McAfee and te Velde (2007) acknowledge the scarcity of, and the need for, empirical studies on yield management. Up to now, this empirical literature has developed two strands. Some studies are aimed at testing the theories of pricing in the airline and other related industries, while the other strand looks at more practical aspects of yield management, including studying the differences in application of this pricing technique to business and leisure passengers and markets. Our study is more closely linked to the latter of this empirical literature.

The following works are most closely related to our paper. Salanti et al. (2012) demonstrate that prices offered by easyJet on predominantly leisure markets show less dynamic behavior as compared to prices on markets with predominantly business traffic. Malighetti et al. (2010) show that Ryanair's price setting tactics have recently developed towards a less dynamic pattern, so that the discounts offered by the carrier for tickets purchased in advance are not as steep as they used to be. Abratea et al. (2012) find that European hotels offer last minute discounts for stays on weekdays, but not on weekends, mirroring evidence from the airline industry that pricing is less dynamic on predominantly tourist markets. Balaguer and Pernias (2013) demonstrate, however, that leisure travelers exhibit a higher degree of substitutability between hotels as compared to business customers. Becerra et al. (2013) show that higher quality hotels tend to offer fewer and shallower discounts to all customers. Overall, our study confirms the findings of these empirical works. Yet, we are also able to measure the effectiveness of YM interventions in terms of the number of additional seats sold, in addition to analyzing the effect of competition between the airlines on effectiveness of such interventions.

Studies testing yield management theories of pricing in the airline industry include Escobari and Gan (2007), Escobari (2012), and Puller et al. (2009). The first paper analyzes fare quotes for a number of flights, tracing evolution of offered prices as the departure day nears. The authors also derive a proxy for the load factor at each date of price data collection to evaluate the probability that the flight will be sold out. The main finding is that lower selling probability yields higher price quote, as predicted by the peak load, inventory control models. Escobari (2012) focuses on demand learning by the airlines, 
using similar data. In contrast, Puller et al. (2009) argue that the observed price pattern is consistent with price discrimination rather than YM. All these studies, however, use data generated by a more complex process than the one described by any of the models in the literature. Both papers deal with pricing of non-stop, one-way flights operated by the network airlines, which requires taking into consideration the well-known discrimination between one-way and round-trip passengers. Also, seats on the same aircraft are occupied by origin-destination and transit passengers, and presence of transit passengers can affect pricing of the origin-destination tickets. Our dataset, however, includes fares for what can be considered a largely homogenous product. Indeed, the carriers in our sample focus exclusively on point-to-point travel; they do not discriminate between one-way and round-trip ticket purchasers; and neither offer refundable tickets, nor employ other 'fences'. Importantly, we observe flight-level final load factors and can therefore study whether and to what extent YM, defined as a revision to a pre-determined pricing profile, is practiced by the carriers and how effective it is in raising a flight's load factor.

In contrast to the recent and still under-developed empirical yield management literature, the relevant theoretical body of work is rather well-established. Most of the theoretical papers (e.g., Dana, 1999a and 1999b) have predicted monotonically increasing offered fares as the departure date nears. The recent study by Deneckere and Peck (2012), however, is able to model emergence of downward price adjustments in a competitive equilibrium in situations where the firm set the price based on an over-optimistic demand forecast. Dana (1999a) illustrates in a model with demand uncertainty and perishable assets, how systematic peak load pricing can be effectively managed by dividing the total of the aircraft's seats into groups or 'buckets' (McGill and Van Ryzin, 1999). The number and size of the buckets depend on the number of possible demand states and their probability of occurring; and by assigning to each bucket a fare whose level is inversely related with the probability that a seat in that group is sold. An important feature of this pricing profile is that it is designed before demand is known: thus any possible revisions of this profile can be classified as stochastic peak load pricing. Dana (1999b) proposes a mechanism to shift demand from peak to off-peak flights when airlines ex-ante do not know for which flight the peak will be realized: because in equilibrium the airline restricts the size of the low-priced buckets, some consumers choose to fly at their least preferred time.

Advance-Purchase Discounts (APD, hereafter) play a separate important role in the relevant theoretical literature. APD provide a simple way to screen consumers by their demand uncertainty. Gale and Holmes (1993) argue that in a monopoly with capacity constraints and perfectly predictable demand, APD are used to divert demand from peak periods to off-peak periods in order to maximize profits. By doing so, the airlines price discriminate across customers on the basis of their price elasticity and time valuation. Similarly, when the demand is uncertain APD help to improve profitability by spreading customers evenly across flights before the peak period is known (Gale and Holmes, 1992). More recently, Möller and Watanabe (2010) compare APD with clearance sales, and illustrate how the former are more appropriate when a consumer faces no or little risk of 
being rationed.

Also related to our study is the literature on price dispersion in industries characterized by costly capacity, asset perishability, and demand uncertainty. Studies of price dispersion in the airline industry include Borenstein and Rose (1994), Gerardi and Shapiro (2009), Gaggero and Piga (2011), Stavins (2001), Hayes and Ross (1998), Hernandez and Wiggins (2009). Of these, Hayes and Ross (1998) and Stavins (2001) suggest the link between the strategies attributed to yield management and observed price dispersion. However, neither of the two studies have a rich enough dataset to offer a more comprehensive analysis of the issue.

\section{Data}

Our dataset consists of three parts. First, we use information on offered prices (fare quotes in British Sterling £) of the two leading European LCCs: easyJet and Ryanair. ${ }^{1}$ The price quotes have been collected on 130 routes both within the United Kingdom, and between the United Kingdom and a number of European countries. ${ }^{2}$ We have used an 'electronic spider' to collect fare quotes by connecting daily and directly to the carriers' web sites from June 2002 until June 2003. Overall, we have identified 843 unique flight codes, served by the two carriers. Fare quotes were collected 1, 4, 7, 10, 14, 21, 28, 35, 42, 49, 56, 63 and 70 days prior to the departure day for each flight. Each of these is denoted as a 'booking day'. The higher frequency of late booking days is meant to allow possible APD effects, an issue that appears to be particularly relevant for both these airlines, as illustrated in Dobson and Piga (2013). Overall, we have collected thirteen fare quotes for each flight.

The second data source we use is the information on final load factors. Specifically, the U.K. Civil Aviation Authority provided daily data on all the flights operated by our two LCCs, easyJet and Ryanair (but not for all the other competitors). This dataset contains information on the flight frequency, as well as on the number of passengers and the available seat capacity of each flight code departing on a given day. Constructing load factors from this data is a simple exercise - the number of final passengers is divided by the aircraft's capacity. In our dataset, the average load factor is 78 percent, with a standard deviation of 15.71 percent. The highly strategic nature of such information led the Civil Aviation Authority to the decision to stop selling data with a daily frequency. Therefore, we also use monthly data, also from the U.K. Civil Aviation Authority, to identify the full set of competitors on the route, and to classify the routes into those with high and low

\footnotetext{
${ }^{1}$ easyJet and Ryanair are the two largest low-cost carriers in Europe. The latter is based in Ireland, the former is headquartered in the United Kingdom. Both carriers perform services throughout Europe. In 2010, Ryanair carried over 70 million passengers; easyJet's total for the same year was over 45 million. By this parameter, the carriers are both among the top five European airlines.

${ }^{2}$ Those routes are not the universe of markets served by easyJet and Ryanair, however they are randomly selected to be good representatives of the entire route-population. The countries under consideration are: Austria, Belgium, Check Republic, France, Germany, Greece, Italy, Ireland, the Netherlands, Norway, Spain, Sweden, and Switzerland.
} 
levels of competition. To this purpose, we define a route as an airport pair (e.g., London Gatwick and Rome Fiumicino). A city-pair includes all the airports serving the two cities (e.g., City, Gatwick, Heathrow, Luton and Stansted for London; Ciampino and Fiumicino for Rome). Thus, a route may be operated by a single carrier, but the latter may face competition from other airlines operating in the same city-pair. Competition is measured using the number of airlines present both at the route level and at the city-pair level. We define a market to be highly competitive if there are at least three carriers on the city-pair market and at least two airlines on the airport-pair market, or if the number of airlines present in the city-pair is at least five, irrespective of the number of airlines serving the given airport-pair market; thus if a route is a monopoly within a very competitive city-pair, it is classified as competitive. The average Herfindahl index across city-pair markets in this sub-sample of competitive routes is 0.28. By contrast, the city-pair market Herfindahl index for the sub-set of non-competitive markets is $0.56 .^{3}$

Finally, the third source we use is the International Passenger Survey (IPS), which is prepared and managed by the U.K. Office for National Statistics and distributed via the U.K. Data Archive. The survey is a random sample of about two percent of passengers entering/leaving the U.K. by air. It provides quarterly information on expenditure levels and passenger characteristics, including the purpose of the journey. For each route, we aggregate the survey information across carriers to derive a set of measures indicating the percentage of passengers traveling for a specific reason. More precisely, for each quarter we measure the share of passengers reporting the following purpose for the journey: $i$ ) holiday \& leisure; $i i$ ) visiting friends \& relatives (VFR), and $i i i$ ) business. We then define the Tourism variable as the sum of the shares of holiday and VFR passenger traffic on the route in the given quarter.

About half of our observations come from routes we classify as competitive. We should also note that the median share of tourist traffic as we defined it here is 85 percent, with at least a quarter of passengers classified as 'tourists' on every route in our sample. These descriptive statistics largely confirm the common impression of LCCs as the airlines catering predominantly to leisure passengers. Yet, we do have a good number of markets where easyJet and Ryanair appear to have attracted a sizeable share of business traffic.

\subsection{Descriptive evidence}

Table 1 reports descriptive statistics (average fare quotes and corresponding standard deviations) depending on how far in advance the fare quotes have been collected. The numbers are reported both for the entire sample, and for several sub-samples. Specifically, we report the descriptive statistics for subsets of competitive and not competitive routes, as well as for the sub-samples of what we define as tourist versus non-tourist markets. The set of tourist markets is defined as routes where the share of passengers traveling on

\footnotetext{
${ }^{3}$ Note also that for each route the competition variable is highly stable (i.e., the classification of a route as competitive or non-competitive very rarely changes over the sample period). Evidence is available upon request.
} 
holiday or to visit friends and relatives is higher than the sample median.

Based on Table 1, price quotes depict a generally increasing trend as the flight date nears; moreover, prices tend to be higher on routes that are less competitive. The difference in offered price dynamics across tourist versus non-tourist routes is quite interesting. For booking days further away from the flight departure date, price quotes on tourist routes tend to be higher than same on non-tourist markets. However, the difference becomes negligible as the flight departure date nears.

Furthermore, our dataset includes a potentially non-trivial number of cases of decreases in offered price over time. Specifically, the average price quote 21 days prior to departure is lower than the same a week before. This difference is observed in all sub-samples except for the subset of non-tourist routes.

To identify the intensity of the YM intervention, we construct the variable Price Decrease, which is a weighted average of fare reductions across the booking day series. To focus on fare reductions that are clearly non-random, and realizing that, for early booking days, a single fare reduction may reflect the chosen, predetermined pricing profile of a carrier's template, we define a sustained fare reduction in the following way. For booking dates from 70 to 21 days before the departure, a price drop is identified as the instance of a lower fare quote for two consecutive dates of data collection. That is: $P_{t} \leq P_{t-1}-£ 5 \leq P_{t-2}-£ 5$. Thus, the fare reduction, in addition to being persistent over two early booking days, has to be also economically relevant, and be at least equal to $£ 5$. Because of the robust evidence that airlines generally do not reduce fares when the departure date is very near (see, e.g., Dobson and Piga, 2013), we consider any sizable fare decrease occurring within a fortnight of the departure date as a manifestation of an YM intervention. Thus, for booking days from 14 to 1 day prior to departure, any relevant fare decrease is counted, i.e., a fare decrease is recorded if $P_{t} \leq P_{t-1}-£ 5$. The variable Price Decrease is then obtained as the weighted average of all relevant price reductions, with higher weights given to discounts originating from higher fare levels. ${ }^{4}$

Price Decrease denotes a single flight-level measure summarizing the price reductions occurring during the flight's booking period. Table 2 reports the average magnitude of each price reduction that we use to construct Price Decrease. The following stylized facts stand out. First, price can fall at any time before the flight departure date; the highest frequency of reduction in price is observed between four and two weeks prior to departure. Second, we are least likely to observe falling fare quotes within the last week prior to a flight departure. Third, the average price reduction ranges between $£ 15$ and $£ 20$, except during the last ten days, when the bounds shift to $£ 25-30$. It is noteworthy that the latter fare reduction occurs with much less frequency and probably represents those few cases where the airline has sold fewer seats than planned and offers larger unexpected discounts hoping to fill up the aircraft. Fourth, easyJet and Ryanair exhibit similar magnitude of average price reduction across booking days; however easyJet shows a higher number of

\footnotetext{
${ }^{4}$ Suppose we identify three instances of relevant price drops for a flight: from $£ 100$ to $£ 80$, from $£ 70$ to $£ 55$ and from $£ 50$ to $£ 40$. Price Decrease is then equal to: $\frac{100}{220} 20+\frac{70}{220} 15+\frac{50}{220} 10 \simeq 18.41$
} 
Table 1: Average Price across Booking Days

\begin{tabular}{|c|c|c|c|c|c|}
\hline $\begin{array}{c}\text { Booking } \\
\text { Days }\end{array}$ & $\begin{array}{l}\text { Full sample } \\
\text { All Routes }\end{array}$ & $\begin{array}{c}\text { Low Comp. } \\
\text { Routes }\end{array}$ & $\begin{array}{c}\text { High Comp. } \\
\text { Routes }\end{array}$ & $\begin{array}{l}\text { Tourist } \\
\text { Routes }\end{array}$ & $\begin{array}{c}\text { Non-tourist } \\
\text { Routes }\end{array}$ \\
\hline $\bar{~} 1$ & $\begin{array}{c}82.6 \\
(43.86)\end{array}$ & $\begin{array}{c}91.5 \\
(44.1)\end{array}$ & $\begin{array}{c}73.7 \\
(41.7)\end{array}$ & $\begin{array}{c}83.2 \\
(42.8)\end{array}$ & $\begin{array}{c}81.8 \\
(45.2)\end{array}$ \\
\hline 4 & $\begin{array}{c}62.8 \\
(37.21)\end{array}$ & $\begin{array}{l}70.5 \\
(39)\end{array}$ & $\begin{array}{c}55 \\
(33.5)\end{array}$ & $\begin{array}{c}63.2 \\
(36.4)\end{array}$ & $\begin{array}{c}62.2 \\
(38.3)\end{array}$ \\
\hline 7 & $\begin{array}{c}49.9 \\
(35.2)\end{array}$ & $\begin{array}{c}55.9 \\
(37.6)\end{array}$ & $\begin{array}{c}43.6 \\
(31.3)\end{array}$ & $\begin{array}{l}51.5 \\
(35)\end{array}$ & $\begin{array}{c}47.6 \\
(35.4)\end{array}$ \\
\hline 10 & $\begin{array}{c}46.3 \\
(34.73)\end{array}$ & $\begin{array}{c}51.7 \\
(36.5)\end{array}$ & $\begin{array}{c}40.7 \\
(31.8)\end{array}$ & $\begin{array}{c}47.6 \\
(34.5)\end{array}$ & $\begin{array}{c}44.5 \\
(34.9)\end{array}$ \\
\hline 14 & $\begin{array}{c}41.6 \\
(32.69)\end{array}$ & $\begin{array}{c}46.7 \\
(34.4)\end{array}$ & $\begin{array}{c}36.2 \\
(29.9)\end{array}$ & $\begin{array}{l}43.9 \\
(33.2)\end{array}$ & $\begin{array}{c}38.5 \\
(31.7)\end{array}$ \\
\hline 21 & $\begin{array}{c}38.2 \\
(31.37)\end{array}$ & $\begin{array}{c}43 \\
(32.9)\end{array}$ & $\begin{array}{c}33.2 \\
(28.8)\end{array}$ & $\begin{array}{c}40.8 \\
(32.4)\end{array}$ & $\begin{array}{c}34.7 \\
(29.6)\end{array}$ \\
\hline 28 & $\begin{array}{c}39.0 \\
(35.04)\end{array}$ & $\begin{array}{c}43.6 \\
(36.8)\end{array}$ & $\begin{array}{c}34.2 \\
(32.4)\end{array}$ & $\begin{array}{c}42.7 \\
(37.2)\end{array}$ & $\begin{array}{c}34 \\
(31.1)\end{array}$ \\
\hline 35 & $\begin{array}{c}34.5 \\
(30.15)\end{array}$ & $\begin{array}{c}38.6 \\
(31.3)\end{array}$ & $\begin{array}{c}30.2 \\
(28.3)\end{array}$ & $\begin{array}{c}37.8 \\
(31.8)\end{array}$ & $\begin{array}{c}29.9 \\
(27.1)\end{array}$ \\
\hline 42 & $\begin{array}{c}32.4 \\
(28.43)\end{array}$ & $\begin{array}{c}36.1 \\
(29.7)\end{array}$ & $\begin{array}{c}28.6 \\
(26.5)\end{array}$ & $\begin{array}{c}35.6 \\
(30.1)\end{array}$ & $\begin{array}{c}28.1 \\
(25.3)\end{array}$ \\
\hline 49 & $\begin{array}{c}31.1 \\
(27.22)\end{array}$ & $\begin{array}{c}34.5 \\
(27.9)\end{array}$ & $\begin{array}{c}27.6 \\
(26.1)\end{array}$ & $\begin{array}{c}34.3 \\
(29.1)\end{array}$ & $\begin{array}{c}26.8 \\
(23.7)\end{array}$ \\
\hline 56 & $\begin{array}{c}29.1 \\
(25.65)\end{array}$ & $\begin{array}{c}32.1 \\
(26.7)\end{array}$ & $\begin{array}{c}26 \\
(24.1)\end{array}$ & $\begin{array}{c}32.1 \\
(27.4)\end{array}$ & $\begin{array}{c}24.9 \\
(22.5)\end{array}$ \\
\hline 63 & $\begin{array}{c}30.5 \\
(25.77)\end{array}$ & $\begin{array}{c}33.6 \\
(26.2)\end{array}$ & $\begin{array}{c}27.3 \\
(24.9)\end{array}$ & $\begin{array}{c}33.6 \\
(27.6)\end{array}$ & $\begin{array}{c}26.3 \\
(22.3)\end{array}$ \\
\hline 70 & $\begin{array}{c}28.6 \\
(24.69)\end{array}$ & $\begin{array}{c}31.4 \\
(25.9)\end{array}$ & $\begin{array}{l}25.6 \\
(23)\end{array}$ & $\begin{array}{c}31.5 \\
(26.6)\end{array}$ & $\begin{array}{c}24.6 \\
(21.1)\end{array}$ \\
\hline
\end{tabular}

(a) Average price across booking days, standard errors in parentheses.

(b) Price is a one-way fare, measured in British Sterling (£) excluding taxes and airport charges.

(c) For the definition of low competitive routes (Low Comp.), highly competitive routes (High Comp.), tourist and non-tourist routes see Section 6.2. 
instances of fare reduction between four and two weeks prior to departure (see also Bachis and Piga, 2011).

Table 2: Price reduction across companies and booking days.

\begin{tabular}{|c|c|c|c|c|c|c|}
\hline & easyJet & easyJet & Ryanair & Ryanair & All sample & All sample \\
\hline $\begin{array}{c}\text { Booking } \\
\text { days }\end{array}$ & $\begin{array}{c}\text { Mean } \\
\text { price } \\
\text { reduction, } \\
\text { in } £\end{array}$ & $\begin{array}{c}\text { Percentage } \\
\text { of flights } \\
\text { with price } \\
\text { reduction }\end{array}$ & $\begin{array}{c}\text { Mean } \\
\text { rice } \\
\text { reduction, } \\
\text { in } £\end{array}$ & $\begin{array}{c}\text { Percentage } \\
\text { of flights } \\
\text { with price } \\
\text { reduction }\end{array}$ & $\begin{array}{c}\text { Mean } \\
\text { price } \\
\text { reduction, } \\
\text { in } £\end{array}$ & $\begin{array}{c}\text { Percentage } \\
\text { of flights } \\
\text { with price } \\
\text { reduction }\end{array}$ \\
\hline 4-1 & 30.50 & 3.55 & 32.25 & 8.88 & 31.82 & 6.54 \\
\hline $7-4$ & 24.59 & 1.76 & 23.99 & 4.83 & 24.12 & 3.50 \\
\hline $10-7$ & 29.40 & 8.01 & 24.46 & 15.18 & 25.9 & 12.03 \\
\hline $14-7$ & 17.79 & 22.69 & 16.90 & 11.19 & 17.44 & 16.19 \\
\hline $21-14$ & 18.04 & 10.09 & 18.29 & 7.18 & 18.16 & 8.44 \\
\hline $28-21$ & 19.33 & 20.12 & 20.96 & 9.33 & 19.94 & 14.02 \\
\hline $35-28$ & 15.51 & 11.24 & 14.58 & 8.49 & 15.05 & 9.68 \\
\hline $42-35$ & 14.59 & 6.05 & 16.64 & 10.42 & 16.00 & 8.52 \\
\hline $49-42$ & 14.20 & 6.45 & 14.78 & 9.59 & 14.59 & 8.24 \\
\hline $56-49$ & 15.09 & 8.57 & 14.46 & 9.67 & 14.70 & 9.20 \\
\hline $63-56$ & 14.26 & 9.06 & 15.72 & 12.71 & 15.20 & 11.15 \\
\hline $70-63$ & 12.98 & 8.73 & 17.57 & 12.33 & 15.95 & 10.76 \\
\hline Average & 17.79 & 9.53 & 18.55 & 9.56 & 18.22 & 9.55 \\
\hline
\end{tabular}

To informally evaluate whether Price Decrease impacts on the final load factor, we consider whether for the same flight (i.e., same flight code, departure time and day of the week) a higher level of Price Decrease today relative to a week ago is positively associated with a higher level of load factor for today's flight. Figure 1 thus plots on the Y-axis the difference of the load factor between two flights in consecutive weeks, while the $\mathrm{X}$-axis represents the same difference for the Price Decrease variable; each curve corresponds to a different flight code. If the flight today has received a stronger treatment (i.e., a higher Price Decrease), this should then be reflected in a higher load factor, that is, in a positive slope of the curves. The figure comprises two business routes (London Luton Paris Charles de Gaulle, served by easyJet, and London Stansted - Frankfurt Hahn, served by Ryanair) and two tourist routes (London Stansted - Alicante, served by easyJet, and London Stansted - Alghero, served by Ryanair). The four diagrams indicate a positive relationship in each route between the level of Price Decrease and the final load factor, which we interpret as prima facie evidence that YM interventions are likely to play a crucial role in improving a flight's load factor. 
Figure 1: Delta Load Factor over Delta Price Decrease
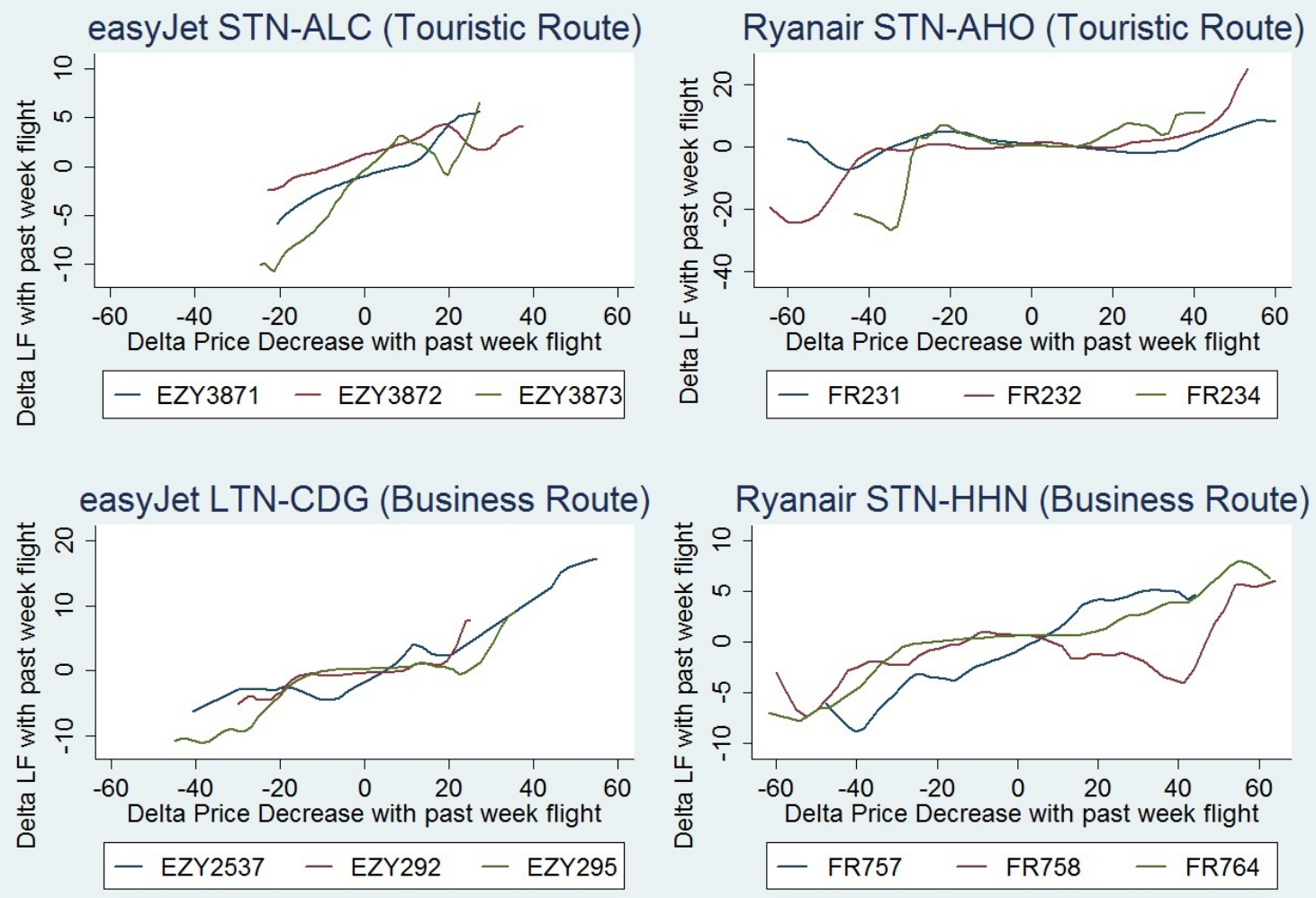

\section{Methodology and Econometric Model}

Our goal is to measure the causal impact of YM interventions on the final flight load factor. In the process, we need to address a number of econometric challenges. First, YM intervention must be clearly defined. While we cannot really say which price profile would be considered atypical by a yield manager, and interventions can take such various forms as increasing the price by a larger magnitude than originally planned or postponing the planned price increase by dropping the lowest available price, our focus on price decreases provides a clearly observable YM intervention which runs contrary to many theoretical models that predict a (non-strictly) monotonic profile of fares. Our second challenge involves dealing with the flight-specific heterogeneity, which we will address via the flightlevel fixed effects model. Last but not least, YM interventions are clearly endogenous, since they are triggered by the same unobserved (by the econometrician) factors that determine load factors; this calls for the adoption of an instrumental variable approach.

Before introducing the econometric model, we further discuss the rationale underlying 
the choice of Price Decrease as a relevant measure of YM intervention; the discussion is also useful to clarify the strategy used to derive its instruments. We propose that we can separate and gauge the net impact of YM interventions by exploiting a number of aspects that characterize the airlines' pricing behavior. Specifically, the intertemporal profile of fares induced by discriminatory purposes tends to be flight-specific and is generally repeated over time. By definition, price decreases induced by YM interventions are idiosyncratic, and therefore flights with such interventions will exhibit a deviation from the typical temporal profile. Furthermore, given the clear evidence of fares increasing sharply in the last ten days before departure, we argue that sustained fare reductions as the departure date nears are consistent with dynamic pricing, but not with intertemporal price discrimination. We essentially suppose that the airline practicing intertemporal price discrimination sets its offered prices according to some profile, which is determined based on some averaged information about demand. More precisely, following Dana (1999a), the airline determines ex ante the dynamics for moving its seat inventory for a given flight across the pre-determined price buckets. ${ }^{5}$ Then, if demand realization is different from that expected 'average', the airline uses yield management to 'manually' move seats across the price buckets. Specifically, when seats are not selling as fast as the profile has predicted, the carrier's yield manager either keeps the seats from moving to higher-priced buckets (i.e., postpones the planned price increase), or moves some of the seat inventory back into the lower-priced buckets (we observe this as the price decrease). However, because the last buckets of seats are already priced so as to reflect high peaks in demand, it is unlikely that when customers arrive at a higher rate than anticipated, a carrier will modify a preset price profile, which already includes automatic increases. Dana (1999b) indeed suggests that booking limits are relaxed more frequently than they are tightened, meaning that yield managers are more likely to react when demand is below projections than when seats are sold faster than expected. Overall, this approach is largely consistent with the description of the YM systems operated by Ryanair and Aer Lingus outlined by the European Commission in its investigation of the merger proposal that was blocked in $2007 .{ }^{6}$ The Commission emphasizes how these carriers adopt a set of standard 'templates' (i.e., a combination of buckets' prices and sizes), whose choice depends on a flight's and its route's characteristics. The templates are expected to remain largely invariant unless, as discussed above, realized demand diverges significantly from its forecast.

The issue is then to identify such interventions. This task is not straightforward, but, in the light of the above suggestions that yield managers are likely to respond to demand realization when it is below its projection, then the only deviation from the pre-determined price trajectory involves cases of reductions in the offered prices over consecutive periods. Therefore, Price Decrease can be used for identifying and quantifying the effects of YM

\footnotetext{
${ }^{5}$ For instance, a certain number of seats could be allocated to some low-price bucket, with the caveat that any of such seats unsold $N$ days prior to departure will move to a higher price bucket, giving rise to the typical 28, 21, 14, 10, 7, and 3-day advance purchase restrictions often observed in the airline industry.

${ }^{6}$ See European Commission (2007) decision on Case No COMP/M.4439 - Ryanair/Aer Lingus, pp. 108-109.
} 
on final load factors.

The baseline econometric specification we will estimate is as follows:

$$
\begin{aligned}
\text { LoadFactor }_{i t}= & \beta_{1} \text { MaxPrice }_{i t}+\beta_{2} \text { PriceDecrease }_{i t}+ \\
& +\delta_{1} \mathrm{Xmas}_{t}+\delta_{2} \text { Easter }_{t}+\delta_{3} \text { MidAugust }_{t}+ \\
& +\sum_{k=1}^{6} \gamma_{k} \text { Weekday }_{k t}+\rho_{i}+\varepsilon_{i t}
\end{aligned}
$$

where $t$ indexes time (day of the month), $i$ represents a flight code operated by an airline on a given route in a month. That is, for the same flight code, we assign a different panel identifier to daily flights in different months. Note that under this panel specification, market structure is given, therefore the fixed effect estimator guarantees our estimates not to be biased by any influence of competition. ${ }^{7}$ The use of monthly panels also takes into account possible seasonal effects, which in turn may be associated with a particular choice of the pricing template.

The dependent variable, Load Factor, is the flight's final occupancy rate, previously defined.

Max Price and the previously defined Price Decrease are, respectively, the key variables capturing how systematic and stochastic peak load pricing are managed. The former is the highest of the 13 fares posted on the respective booking days $(70,63 \ldots 1$ days before the flight's scheduled departure day). This measure allows to control for the 'general' (i.e., average) relationship linking fares and load factors; therefore, it gives us the indication of the highest price bucket reached as the airline has been selling seats on a given flight. Because theoretical models of systematic peak load pricing under demand uncertainty predict a monotonically increasing relationship between load factors and fares, so that a higher fare is associated with seats with a lower probability of being sold, we expect the coefficient of Max Price to be positive (Dana, 1999a). ${ }^{8}$ Similarly, we expect flights with more intense price decreases to exhibit a larger increase in the load factor.

The remaining variables control for potential peak demand periods. Xmas, Easter and MidAugust are three indicator variables for flights departing during the week(s) of Christmas \& New Year (winter peak), Easter (spring peak), and August 15th (summer peak), respectively.

Weekday variables are indicators for the day of the week, on which the flight is scheduled (with Wednesdays being the omitted category). Thus, the coefficients on these dummies show how different on average load factors on a given day of the week are relative to those for Wednesday flights.

The flight-code specific heterogeneity (e.g., Ryanair flight FR3768 from London Luton to Girona) will be captured by the corresponding flight-code fixed effects $\rho_{i}$. Then, $\varepsilon_{i t}$

\footnotetext{
${ }^{7}$ This is because airlines keep their flight schedule fixed for a period which is usually longer than a month; e.g., airlines typically operate a winter and a summer schedule.

${ }^{8}$ To properly test this hypothesis is beyond the scope of this paper: to do so, it would be necessary to know the exact number of seats that have already been sold at the time a fare is posted.
} 
represents the idiosyncratic errors that may be correlated both serially and with errors for other observations within a route. To correctly account for these properties of disturbances in estimation, our standard errors will be clustered by route and week. This will capture the possibility of flight-specific demand shocks on a given day affecting the demand for all of the flights on the route in a given week. For instance, a large group booking for a Wednesday morning flight may raise fares for this flight, and lead to customers switching to other flights of the same airline on nearby days, or to flights of the competing carrier(s).

Our biggest econometric challenge comes from the fact that unobserved shocks affecting load factors also influence the highest price quote observed. Consequently, unobserved shocks affecting our dependent variable can also influence the implementation of YM by the airlines. Thus, since both of our key independent variables are correlated with the error term, we address this problem by using an instrumental variable approach.

We use the following variables as instruments:

- Average highest price quote for the same flight, observed one and two weeks before and after the given flight date. For example, for a flight departing on a Monday, we construct this instrument as the average of the highest price quotes for the same flight departing on the two previous and the two next Mondays.

- Average value of Price Decrease from the flights departing within the two weeks preceding and following the current week. Similarly to the way we constructed our previous instrument, for a flight departing on a Monday, we calculate the average of Price Decrease for the same flight departing on the two previous and the two following Mondays.

Thus, both instruments are constructed by using lags and leads of the endogenous variables. That is, they are likely to be correlated with, respectively, the endogenous regressors Max Price and Price Decrease, but they should not be with $\varepsilon_{i t}$, since the latter is unlikely to be influenced by shocks in demand that have affected one- or two-weeks old flights, and it is unlikely to influence similarly distanced future flights. Assuming that $\varepsilon_{i t}$ is uncorrelated with the value of the instruments based on flights taken at $t \pm 7$ or $t \pm 14$ implies that the effect of a shock is short-lived: any shock at time $t$ is unlikely to be transmitted to the flights that have left or will leave 7 or 14 days before or after $t .^{9}$

- Number of booking days (NOT flight departure days) falling in the holiday period (weeks of Christmas, Easter, and August 15th). We argue that in such periods, the airlines may find it more difficult to monitor closely all their operations, due to, e.g., staffing shortages. In such a case, the airline would rely more on standard YM

\footnotetext{
${ }^{9}$ For a chain effect to occur (a shock on a Monday affects the Tuesday flight, which affects the Wednesday flight etc, so that eventually the shock affects the flight on the following Monday), it would be necessary that every day the flights are filled to capacity, which would force substitutability across days. However, it is highly unlikely that all flights in a week fly full.
} 
practices that entail few or no diversion from a preset pricing profile, leaving little room for discretionary YM interventions, such as price decreases. The underlying idea is that, on one hand, there is less YM intervention during the holiday period. On the other, there is no direct correlation between the load factor and the holiday period; that is, flights whose fares are sampled also during a holiday period are not necessarily emptier or fuller than those flights whose fares are not sampled during the holiday period. These aspects, which would make this variable a valid instrument for YM, can be tested using the Hansen test. ${ }^{10}$

It is stress-worthy that the aim of our econometric exercise is to quantify the effect of discretionary YM interventions, captured by the endogenous regressor Price Decrease, on a flight's final load factor, net of the impact due to systematic peak load pricing as reflected by Max Price. Because such effects are evaluated at the single flight's level, the quantity-price relationship cannot be considered as an instance of a demand schedule for a number of reasons. First, none of the instruments identifies a cost shifter. Second, on a number of markets higher expected demand will result in the airline scheduling an additional flight. A proper demand estimation would consider the total number of seats sold on separate flights on a market, while here we treat each flight as a separate entity. Third, supply of seats in our data is very rigid: both airlines adhere to a single-aircrafttype business model. For example, Ryanair can only offer capacity on the market in 189-seat supplements (capacity of the Boeing aircraft operated by this carrier). Imagine two markets served by Ryanair, one supporting 150 passengers per day, and the other attracting 250 travelers daily, other things equal. Clearly, demand level is higher on the latter market. However, if Ryanair scheduled one daily flight on the former route, and two daily departures on the latter, due to the aircraft's capacity constraints it faces, we would observe higher load factors on the former, low-demand market. This last example also suggests that our estimates cannot be interpreted in terms of a supply function, whose estimation would require data on the composition of each 'price-bucket size' combination. However, as far as the instruments based on lead and lags are concerned, they capture variations in demand conditions that help trace out both the increasing pricing profile due to systematic peak load pricing and the positive impact of discretionary YM interventions in the form of price drops.

To verify the validity of our instruments, we use the Hansen test for overidentifying restrictions. If the test fails to reject the null hypothesis, then all instruments used are considered exogenous. We will report this test in all the tables. To anticipate the results, the Hansen test clearly supports our choice of instruments - the null hypothesis is never rejected at conventional significance levels. To demonstrate that the instruments we have chosen are not weak (i.e., that they are actually correlated with the endogenous variables), first-stage regression results for the two-stage least squares estimation for some of our

\footnotetext{
${ }^{10}$ Different pricing for the same service based on different period of purchase (i.e. working days vs. holidays) is documented in the airline industry by Puller and Taylor (2012), who find that tickets bought during the weekend are, on average, five percent cheaper than similar tickets bought during weekdays.
} 
specifications are presented in Table 7 in the Appendix. This is done in addition to employing the Cragg and Donald (1993) test. This test has been suggested by Stock and Yogo (2005) as a test for the presence of weak instruments. This is essentially an F-test, with null hypothesis being underidentification - largely rejected in all our estimates.

\section{$5 \quad$ Results}

Our econometric strategy will be as follows. We will start by presenting the results for the entire sample. Both the Generalized Least Squares (GLS) and Two-Stage Least Squares (2SLS) estimation results will be reported, to demonstrate that the use of the instrumental variable technique fundamentally changes the coefficients on the key independent variables. Next, we will examine whether the effect of YM on load factor depends on the level of competition and on the share of holiday and visiting friends \& relatives (VFR) traffic on the route. A priori we expect a higher impact of YM on more competitive routes, as demand on these routes is likely to be more price sensitive. As for the differences in the impact of YM depending on the share of tourist traffic on the route, the relationship here is more complex. On one hand, as leisure passengers tend to be more price sensitive that business passengers, we can expect a higher impact of YM interventions on tourist routes. On the other hand, travel uncertainty tends to be realized sooner for leisure passengers, and last minute drops in offered prices may not induce that much demand on tourist routes. Finally, we will replace Max Price with different measures of average offered price, as well as the simple range of offered prices, as robustness checks of our results.

\subsection{Baseline results}

Estimation results of equation (1) for the entire sample are reported in Table 3. Column (1) reports the GLS Fixed Effects estimates, which are included primarily to gauge the impact of the instruments. To check for the presence of endogeneity we apply the Hausman (1978) test between the models '2SLS' and 'GLS Fixed Effects'. The test produces a $\chi^{2}$ value equal to 18.53 , which is statistically significant at a critical value below $7 \%$; hence, we reject the null hypothesis of exogeneity. Cragg and Donald (1993) test results suggest that our instruments are not weak. Columns (2) and (3) in Table 3 report 2SLS fixed effects results. Column (3) presents the results of the specification using the natural logarithm of load factor as dependent variable. Columns (4) and (5) are the equivalent of respectively columns (1) and (2), differing only by the use of the Number of Price Drops as an alternative measure of YM intervention in place of Price Decrease. ${ }^{11}$ While in principle we could have flights with the same value of Price Decrease and a different Number of

\footnotetext{
${ }^{11}$ The Number of Price Drops measures the frequency of fare reduction occurring during a flight's booking period; fare reductions are identified in the same way used to construct Price Decrease (see Section 3.1). Similarly, the Number of Price Drops is instrumented using the average number of price drops for the flights departing within the two weeks preceding and following the current week.
} 
Price Drops (or vice versa), the use of the two variables leads to very similar results, as Table 3 shows.

Relative to those in Column (1), the results reported in Column (2) indicate that when the instrumental variable technique is applied, the coefficient of the Price Decrease variable changes sign but remains highly significant. When we do not account for endogeneity of this variable, we find that higher price decreases are associated with lower load factors. Such negative correlation is consistent with the view that a larger value of Price Decrease is likely to be observed in flights whose performance is worse than expected. However, as it is standard in these cases, the GLS is not consistently estimating the causal effect of the YM interventions. Indeed, the GLS estimates measure the difference in the expected load factors of two arbitrary flights with the same characteristics, except that their value of Price Decrease differs by one unit. What we are interested in measuring is the expected load factor difference if on an arbitrary flight the yield manager (for some exogenous reasons) decides to increase the value of Price Decrease by one unit.

Interestingly, when endogeneity is taken into account, the causal interpretation of the coefficient on Price Decrease is in accordance with our expected hypothesis: a price decrease appears to be effective in raising the load factors. Furthermore, moving the attention to the other endogenous regressor, a higher maximum price is associated with higher load factors. This is in line with the theoretical predictions in Dana (1999b) that carriers ex-ante allocate seats into buckets (or fare classes), moving the seat inventory into higher priced buckets as the plane fills up.

The magnitudes of the estimated effects of price and YM are as follows. Taking the coefficient on Max Price in the model '2SLS' of Column (2), a one standard deviation increase of Max Price is associated with an increase in the Load Factor by about 5.5 percent. Also (based on 2SLS result), one standard deviation increase in the Price Decrease variable raises Load Factor by about 2.7 percent. For a typical Ryanair's 189-seat aircraft, this translates into about 5 additional seats sold as a result of the application of an YM approach aimed at lowering the offered price in response to unusually slow realization of demand, holding everything else constant. Similar qualitative results are obtained when Price Decrease is replaced with the Number of Price Drops. Quantitatively the effect of the Number of Price Drops on load factor is slightly lower: one standard deviation increase in the Number of Price Drops on average raises Load Factor by about 1.3 percent, which translates into about 2.5 additional seats sold.

As far as the remaining control variables are concerned, we observe that load factors are higher on average on certain days of the week, and during some of the higher demand periods. More interestingly the positive sign found across the six dummy variables representing the day of the week suggests that flights departing on Wednesdays have the lowest load factor. ${ }^{12}$ Finally, it is noteworthy that using a specification in log of the Load Factor variable - Column (3) in Table 3 - does not alter the qualitative interpretations of the

\footnotetext{
${ }^{12}$ Recall that Wednesdays is the reference category of the day-of-the-week dummy group, and therefore the positive sign on the other dummies measures the average increase in the load factor of the observed day with respect to Wednesday.
} 
Table 3: Baseline results.

\begin{tabular}{|c|c|c|c|c|c|}
\hline & $\begin{array}{c}(1) \\
\text { GLS FE }\end{array}$ & $\begin{array}{c}(2) \\
\text { 2SLS FE }\end{array}$ & $\begin{array}{c}(3) \\
\text { 2SLS FE }\end{array}$ & $\begin{array}{c}(4) \\
\text { GLS FE }\end{array}$ & $\begin{array}{c}(5) \\
\text { 2SLS FE }\end{array}$ \\
\hline Max Price & $\begin{array}{c}0.149^{* * *} \\
(0.002)\end{array}$ & $\begin{array}{c}0.123^{* * *} \\
(0.012)\end{array}$ & $\begin{array}{c}0.002^{* * *} \\
(0.000)\end{array}$ & $\begin{array}{c}0.148^{* * *} \\
(0.002)\end{array}$ & $\begin{array}{c}0.135^{* * *} \\
(0.010)\end{array}$ \\
\hline Price Decrease & $\begin{array}{c}-0.012^{* * *} \\
(0.004)\end{array}$ & $\begin{array}{c}0.189^{* *} \\
(0.091)\end{array}$ & $\begin{array}{c}0.003^{* *} \\
(0.002)\end{array}$ & & \\
\hline Number Price Drops & & & & $\begin{array}{c}-0.238^{* * *} \\
(0.066)\end{array}$ & $\begin{array}{l}1.253^{*} \\
(0.749)\end{array}$ \\
\hline Sundays & $\begin{array}{c}1.856^{* * *} \\
(0.232)\end{array}$ & $\begin{array}{c}1.910^{* * *} \\
(0.329)\end{array}$ & $\begin{array}{c}0.028^{* * *} \\
(0.006)\end{array}$ & $\begin{array}{c}1.874^{* * *} \\
(0.231)\end{array}$ & $\begin{array}{c}1.980^{* * *} \\
(0.311)\end{array}$ \\
\hline Mondays & $\begin{array}{c}3.670^{* * *} \\
(0.191)\end{array}$ & $\begin{array}{c}3.863^{* * *} \\
(0.234)\end{array}$ & $\begin{array}{c}0.066^{* * *} \\
(0.004)\end{array}$ & $\begin{array}{c}3.669^{* * *} \\
(0.191)\end{array}$ & $\begin{array}{c}3.863^{* * *} \\
(0.238)\end{array}$ \\
\hline Tuesdays & $\begin{array}{c}0.665^{* * *} \\
(0.164)\end{array}$ & $\begin{array}{c}0.670^{* * *} \\
(0.168)\end{array}$ & $\begin{array}{c}0.012^{* * *} \\
(0.003)\end{array}$ & $\begin{array}{c}0.662^{* * *} \\
(0.164)\end{array}$ & $\begin{array}{c}0.684^{* * *} \\
(0.166)\end{array}$ \\
\hline Thursdays & $\begin{array}{c}2.588^{* * *} \\
(0.156)\end{array}$ & $\begin{array}{c}2.572^{* * *} \\
(0.195)\end{array}$ & $\begin{array}{c}0.044^{* * *} \\
(0.003)\end{array}$ & $\begin{array}{c}2.599^{* * *} \\
(0.156)\end{array}$ & $\begin{array}{c}2.605^{* * *} \\
(0.189)\end{array}$ \\
\hline Fridays & $\begin{array}{c}2.685^{* * *} \\
(0.218)\end{array}$ & $\begin{array}{c}2.778^{* * *} \\
(0.300)\end{array}$ & $\begin{array}{c}0.042^{\text {*** }} \\
(0.005)\end{array}$ & $\begin{array}{c}2.711^{* * *} \\
(0.218)\end{array}$ & $\begin{array}{c}2.766^{* * *} \\
(0.294)\end{array}$ \\
\hline Saturdays & $\begin{array}{c}2.327^{* * *} \\
(0.206)\end{array}$ & $\begin{array}{c}2.174^{* * * *} \\
(0.307)\end{array}$ & $\begin{array}{c}0.038^{* * *} \\
(0.005)\end{array}$ & $\begin{array}{c}2.345^{* * *} \\
(0.205)\end{array}$ & $\begin{array}{c}2.302^{* * *} \\
(0.280)\end{array}$ \\
\hline Winter Peak (Xmas) & $\begin{array}{c}2.924^{* * *} \\
(0.652)\end{array}$ & $\begin{array}{c}2.643^{* * *} \\
(0.795)\end{array}$ & $\begin{array}{c}0.035^{* * *} \\
(0.013)\end{array}$ & $\begin{array}{c}2.950^{* * *} \\
(0.652)\end{array}$ & $\begin{array}{c}2.929 * * * \\
(0.753)\end{array}$ \\
\hline Spring Peak (Easter) & $\begin{array}{c}2.640^{* * *} \\
(0.466)\end{array}$ & $\begin{array}{c}2.431^{* * *} \\
(0.566)\end{array}$ & $\begin{array}{c}0.034^{* * *} \\
(0.010)\end{array}$ & $\begin{array}{c}2.623^{* * *} \\
(0.466)\end{array}$ & $\begin{array}{c}2.757^{* * *} \\
(0.531)\end{array}$ \\
\hline Summer Peak (Mid-Aug) & $\begin{array}{c}0.811^{* *} \\
(0.403)\end{array}$ & $\begin{array}{c}0.863^{*} \\
(0.466)\end{array}$ & $\begin{array}{l}0.012^{*} \\
(0.007)\end{array}$ & $\begin{array}{c}0.830^{* *} \\
(0.404)\end{array}$ & $\begin{array}{l}0.707^{*} \\
(0.426)\end{array}$ \\
\hline$R^{2}$ & 0.159 & 0.127 & 0.082 & 0.159 & 0.149 \\
\hline $\begin{array}{l}\text { Cragg-Donald } F \text {-stat } \\
\text { Hansen } \chi^{2}\end{array}$ & & $\begin{array}{c}125.939^{* * *} \\
0.086\end{array}$ & $\begin{array}{c}125.939^{* * *} \\
0.156\end{array}$ & & $\begin{array}{c}392.373^{* * *} \\
0.152\end{array}$ \\
\hline Observations & 106,979 & 106,979 & 106,979 & 106,979 & 106,979 \\
\hline
\end{tabular}

(a) Models (1) and (4) Generalized Least Squares Fixed-Effect. Models (2), (3) and (5) Two-Stage Least Squares.

(b) Dependent variable: Load factor for all models except $\log$ (Load factor) for Model (3).

(c) Estimation technique: flight-code fixed effects with standard errors in parentheses, robust to heteroscedasticity and serial correlation, clustered by route-week.

(d) See text for the list of instruments for Max Price, Price Decrease and Nbr Price Drops.

(e) Coefficients ${ }^{* * *}$ statistically significant at $1 \%, * *$ at $5 \%$ and $*$ at $10 \%$. 
results.

The results reported in Table 3 provide the backdrop against which we investigate the central issue of the paper, namely, whether the effect of an intervention by a yield manager depends on the extent of competition and on the degree of consumer heterogeneity in a route.

\subsection{Competition and Tourism}

We will now evaluate whether the magnitude of the effect of YM interventions differs depending on two factors: the level of competition and the share of leisure passengers on the route. Recall that, within the same month, market structure is fixed. Similarly, as indicated in Gerardi and Shapiro (2009), travelers' motivation remains constant over time, with some routes being predominantly used by leisure travelers, while others by a more heterogeneous mixture of passengers. To study both aspects, we re-estimate equation (1) interacting our two key variables (Max Price and Price Decrease) with indicator variables for routes with low level of competition and for Tourism. ${ }^{13}$

The results of estimating equation (1) including the above-mentioned interaction variables are reported in Table 4. Because we report only 2SLS estimates, it is noteworthy that the instruments - Average highest price quote and Average value of price decrease - are also interacted with the indicator variable for routes with low level of competition, and with the measure of tourist traffic on the route.

Table 4 does not indicate any substantial difference in the effectiveness of YM interventions between competitive and non-competitive routes. While both Max Price and Price Decrease have positive and significant coefficients, their interaction with the Low Comp dummy is insignificant and generally of a small magnitude. The result concerning Max Price is consistent with the view that the ex-ante pricing profile is generated by a standardized YM procedure that appears to be independent of market structure. Quantitatively, the size of both effects is still the same as reported in the previous regressions.

On the contrary, we consistently observe that YM interventions become less effective as the share of leisure and VFR traffic increases. Specifically, because the coefficients of the Price Decrease variable and its interacted term with Tourism are of about the same magnitude but with an inverse sign, the effect of YM interventions on routes with a 50 percent tourist passenger traffic will be about half of what we would observe on the hypothetical route with no tourist traffic. ${ }^{14}$ Moreover, YM interventions become nearly completely ineffective on markets where 100 percent of passengers travel on holiday or to visit friends and relatives.

In light of our discussion above, it appears that YM interventions might have a small effect on routes with a predominant component of tourist traffic; this may reflect the fact

\footnotetext{
${ }^{13}$ Recall that Tourism is defined as the sum of the shares of holiday and VFR passenger traffic on the route in the given quarter.

${ }^{14}$ Recall that we have at least 25 percent holiday and VFR passenger traffic on all the routes in our sample.
} 
Table 4: Different market conditions. Dependent variable: Load factor

\begin{tabular}{|c|c|c|c|}
\hline & (1) & $(2)$ & $(3)$ \\
\hline Max Price & $\begin{array}{c}0.117^{* * *} \\
(0.015)\end{array}$ & $\begin{array}{c}0.194^{* * *} \\
(0.056)\end{array}$ & $\begin{array}{c}0.189^{* * *} \\
(0.057)\end{array}$ \\
\hline (Max Price)*(Low Comp) & $\begin{array}{c}0.013 \\
(0.022)\end{array}$ & & $\begin{array}{c}0.006 \\
(0.023)\end{array}$ \\
\hline$(\text { Max Price })^{*}($ Tourism $)$ & & $\begin{array}{l}-0.083 \\
(0.074)\end{array}$ & $\begin{array}{l}-0.080 \\
(0.075)\end{array}$ \\
\hline Price Decrease & $\begin{array}{c}0.224^{* *} \\
(0.108)\end{array}$ & $\begin{array}{c}1.029^{* * *} \\
(0.384)\end{array}$ & $\begin{array}{c}1.049^{* * *} \\
(0.387)\end{array}$ \\
\hline (Price Decrease)*(Low Comp) & $\begin{array}{c}-0.078 \\
(0.181)\end{array}$ & & $\begin{array}{c}0.082 \\
(0.191)\end{array}$ \\
\hline (Price Decrease)*(Tourism) & & $\begin{array}{c}-1.077^{* *} \\
(0.495)\end{array}$ & $\begin{array}{c}-1.153^{* *} \\
(0.516)\end{array}$ \\
\hline Sundays & $\begin{array}{c}1.909^{* * *} \\
(0.330)\end{array}$ & $\begin{array}{c}1.712^{* * *} \\
(0.334)\end{array}$ & $\begin{array}{c}1.682^{* * * *} \\
(0.339)\end{array}$ \\
\hline Mondays & $\begin{array}{c}3.843^{* * *} \\
(0.234)\end{array}$ & $\begin{array}{c}3.752^{* * *} \\
(0.237)\end{array}$ & $\begin{array}{c}3.743^{* * *} \\
(0.238)\end{array}$ \\
\hline Tuesdays & $\begin{array}{c}0.660^{* * *} \\
(0.169)\end{array}$ & $\begin{array}{c}0.610^{* * *} \\
(0.169)\end{array}$ & $\begin{array}{c}0.617^{* * * *} \\
(0.170)\end{array}$ \\
\hline Thursdays & $\begin{array}{c}2.563^{* * *} \\
(0.193)\end{array}$ & $\begin{array}{c}2.565^{* * *} \\
(0.198)\end{array}$ & $\begin{array}{c}2.560^{* * *} \\
(0.197)\end{array}$ \\
\hline Fridays & $\begin{array}{c}2.768^{* * * *} \\
(0.299)\end{array}$ & $\begin{array}{c}2.717^{* * *} \\
(0.303)\end{array}$ & $\begin{array}{c}2.700^{* * *} \\
(0.303)\end{array}$ \\
\hline Saturdays & $\begin{array}{c}2.178^{* * * *} \\
(0.312)\end{array}$ & $\begin{array}{c}2.199 * * * \\
(0.310)\end{array}$ & $\begin{array}{c}2.176^{* * *} \\
(0.315)\end{array}$ \\
\hline Winter Peak (Xmas) & $\begin{array}{c}2.627^{* * *} * \\
(0.794)\end{array}$ & $\begin{array}{c}2.904^{* * *} \\
(0.736)\end{array}$ & $\begin{array}{c}2.856^{* * *} \\
(0.741)\end{array}$ \\
\hline Spring Peak (Easter) & $\begin{array}{c}2.454^{* * *} \\
(0.574)\end{array}$ & $\begin{array}{c}2.380^{* * *} \\
(0.570)\end{array}$ & $\begin{array}{c}2.312^{* * *} \\
(0.593)\end{array}$ \\
\hline Summer Peak (Mid-August) & $\begin{array}{l}0.898^{*} \\
(0.473)\end{array}$ & $\begin{array}{c}0.927^{* *} \\
(0.463)\end{array}$ & $\begin{array}{l}0.869^{*} \\
(0.466)\end{array}$ \\
\hline$R^{2}$ & 0.131 & 0.122 & 0.116 \\
\hline Cragg-Donald $F$-stat & $42.274^{* * *}$ & $51.488^{* * *}$ & $29.309^{* * *}$ \\
\hline Hansen $\chi^{2}$ & 0.079 & 0.001 & 0.001 \\
\hline Observations & 106,979 & 106,979 & 106,979 \\
\hline
\end{tabular}

(a) Estimation technique: flight-code fixed effects two-stage least squares with standard errors in parentheses, robust to heteroscedasticity and serial correlation, clustered by route-week.

(b) See text for discussion of instruments for Max Price, Price Decrease and interacted terms.

(c) Coefficients $* * *$ statistically significant at $1 \%,{ }^{* *}$ at $5 \%$ and $*$ at $10 \%$. 
that tourists plan their journey in advance, since they have stronger preferences for travel on specific dates. This is the case even though leisure passengers generally tend to be more price sensitive than business passengers. Indeed, our estimation results also suggest that decreasing the highest offered price will increase the load factor on tourist routes.

\subsection{Robustness Checks}

So far, the analysis has controlled for the systematic peak load pricing component by using the highest price bucket. In this section, we will explore alternative measures, which make full use of the observed path of price quotes. Specifically, we alternatively replace Max Price with:

- A weighted average offered fare. Since the distribution of passengers purchasing their ticket may vary across the booking periods (for instance, more tickets might be bought closer to the flight departure date than further away from it, or vice versa), we assume different demand distributions across booking days (i.e., we assign different weights to each offered fare in different booking days), and calculate the average offered prices accordingly. As we noted above, price decreases closer to the departure date are most likely to represent an exercise of discretionary YM interventions, so a stronger relationship between price decrease and load factors in regressions putting more weight on observations closer to the flight departure date will strengthen our modeling approach.

- The difference between the highest and the lowest fare quotes for a given flight on a given date.

Using a weighted average price. In addition to using the simple average, which assigns equal weight to each of the thirteen fare quotes we gathered for every flight, in Table 5 we use three different weighted averages for prices. Difference between them is in the degree of importance assigned to fare quotes observed closer to the flight date. Specifically, Model (2) in Table 5 assigns a 20\% cumulative weight to early booking period (booking days 70-49), a 40\% cumulative weight to middle booking period (booking days $42-14$ ), and a $40 \%$ cumulative weight to late booking period (10-1 booking days). Model (3)'s weights are: $30 \%$ for early booking period, $40 \%$ for middle booking period, and $30 \%$ for late booking period. Next, Model (4) computes the weighted average assigning $40 \%$, $40 \%$, and 20\%, respectively. That is, as we shift from Model (2) towards Model (4) to calculate the weighted average fare, we give more weight to the early booking period and less weight to the late booking period .

In Table 5 we continue reporting results for 2SLS model, where the instrument for Average Price variable is calculated in the same way as the instrument for Max Price -

i.e., taking the mean of average prices for the same flight one and two weeks before and after a given flight's departure. 
Table 5: Weighted average price. Dependent Variable: Load factor

\begin{tabular}{|c|c|c|c|c|}
\hline & $\begin{array}{c}(1) \\
\text { No weights }\end{array}$ & $\begin{array}{c}\text { (2) } \\
\text { Distr. } 1\end{array}$ & $\begin{array}{c}(3) \\
\text { Distr. } 2\end{array}$ & $\begin{array}{c}(4) \\
\text { Distr. } 3\end{array}$ \\
\hline " Average Price & $\begin{array}{c}0.339^{* * *} \\
(0.121)\end{array}$ & $\begin{array}{c}0.331^{* * *} \\
(0.108)\end{array}$ & $\begin{array}{c}0.341^{* * *} \\
(0.115)\end{array}$ & $\begin{array}{c}0.352^{* * *} \\
(0.122)\end{array}$ \\
\hline (Average Price)*(Low Comp) & $\begin{array}{l}-0.057 \\
(0.048)\end{array}$ & $\begin{array}{l}-0.051 \\
(0.043)\end{array}$ & $\begin{array}{l}-0.057 \\
(0.045)\end{array}$ & $\begin{array}{l}-0.063 \\
(0.049)\end{array}$ \\
\hline (Average Price) $)^{*}$ Tourism) & $\begin{array}{l}-0.122 \\
(0.167)\end{array}$ & $\begin{array}{l}-0.140 \\
(0.147)\end{array}$ & $\begin{array}{l}-0.137 \\
(0.156)\end{array}$ & $\begin{array}{l}-0.134 \\
(0.167)\end{array}$ \\
\hline Price Decrease & $\begin{array}{l}1.211^{* *} \\
(0.505)\end{array}$ & $\begin{array}{l}1.110^{* *} \\
(0.484)\end{array}$ & $\begin{array}{l}1.160^{* *} \\
(0.494)\end{array}$ & $\begin{array}{l}1.213^{* *} \\
(0.505)\end{array}$ \\
\hline$($ Price Decrease $) *($ Low Comp $)$ & $\begin{array}{c}0.180 \\
(0.243)\end{array}$ & $\begin{array}{c}0.174 \\
(0.227)\end{array}$ & $\begin{array}{c}0.188 \\
(0.235)\end{array}$ & $\begin{array}{c}0.203 \\
(0.245)\end{array}$ \\
\hline$(\text { Price Decrease })^{*}($ Tourism $)$ & $\begin{array}{c}-1.408^{* *} \\
(0.712)\end{array}$ & $\begin{array}{c}-1.216^{*} \\
(0.669)\end{array}$ & $\begin{array}{c}-1.308^{*} \\
(0.690)\end{array}$ & $\begin{array}{c}-1.407^{* *} \\
(0.715)\end{array}$ \\
\hline Sundays & $\begin{array}{c}1.096^{* * *} \\
(0.398)\end{array}$ & $\begin{array}{c}1.059 * * * \\
(0.391)\end{array}$ & $\begin{array}{c}1.058^{* * *} \\
(0.397)\end{array}$ & $\begin{array}{c}1.057^{* * *} \\
(0.404)\end{array}$ \\
\hline Mondays & $\begin{array}{c}3.550^{* * *} \\
(0.289)\end{array}$ & $\begin{array}{c}3.529^{* * *} \\
(0.283)\end{array}$ & $\begin{array}{c}3.547^{* * *} \\
(0.286)\end{array}$ & $\begin{array}{c}3.567^{* * *} \\
(0.290)\end{array}$ \\
\hline Tuesdays & $\begin{array}{c}0.449^{* *} \\
(0.183)\end{array}$ & $\begin{array}{c}0.452^{* *} \\
(0.181)\end{array}$ & $\begin{array}{c}0.452^{* *} \\
(0.182)\end{array}$ & $\begin{array}{c}0.452^{* *} \\
(0.184)\end{array}$ \\
\hline Thursdays & $\begin{array}{c}2.522^{* * *} \\
(0.204)\end{array}$ & $\begin{array}{c}2.519^{* * *} \\
(0.201)\end{array}$ & $\begin{array}{c}2.522^{* * *} \\
(0.202)\end{array}$ & $\begin{array}{c}2.525^{* * *} \\
(0.205)\end{array}$ \\
\hline Fridays & $\begin{array}{c}2.461^{* * *} \\
(0.343)\end{array}$ & $\begin{array}{c}2.467^{* * *} \\
(0.335)\end{array}$ & $\begin{array}{c}2.463^{* * *} \\
(0.339)\end{array}$ & $\begin{array}{c}2.460^{* * *} \\
(0.345)\end{array}$ \\
\hline Saturdays & $\begin{array}{c}1.592^{* * *} \\
(0.323)\end{array}$ & $\begin{array}{c}1.650^{* * *} \\
(0.316)\end{array}$ & $\begin{array}{c}1.604^{* * *} \\
(0.320)\end{array}$ & $\begin{array}{c}1.555^{* * *} \\
(0.326)\end{array}$ \\
\hline Winter Peak (Xmas) & $\begin{array}{l}1.604^{* *} \\
(0.815)\end{array}$ & $\begin{array}{l}1.718^{* *} \\
(0.781)\end{array}$ & $\begin{array}{c}1.578^{* *} \\
(0.803)\end{array}$ & $\begin{array}{l}1.424^{*} \\
(0.831)\end{array}$ \\
\hline Spring Peak (Easter) & $\begin{array}{l}1.289^{* *} \\
(0.624)\end{array}$ & $\begin{array}{c}1.309^{* *} \\
(0.610)\end{array}$ & $\begin{array}{c}1.258^{* *} \\
(0.620)\end{array}$ & $\begin{array}{l}1.202^{*} \\
(0.633)\end{array}$ \\
\hline Summer Peak (Mid-August) & $\begin{array}{l}1.038 * * \\
(0.473)\end{array}$ & $\begin{array}{l}1.129 * * \\
(0.483)\end{array}$ & $\begin{array}{l}1.065^{* *} \\
(0.479)\end{array}$ & $\begin{array}{c}0.992^{* *} \\
(0.477)\end{array}$ \\
\hline$R^{2}$ & 0.085 & 0.102 & 0.090 & 0.075 \\
\hline Cragg-Donald $F$-stat & $20.153^{* * *}$ & $22.113^{* * *}$ & $21.473^{* * *}$ & $20.692^{* * *}$ \\
\hline Hansen $\chi^{2}$ & 0.032 & 0.035 & 0.077 & 0.142 \\
\hline Observations & 106,979 & 106,979 & 106,979 & 106,979 \\
\hline
\end{tabular}

(a) Models (2)-(4) differ in weights used in calculation of Average Price. See text for description.

(b) Estimation technique: flight-code fixed effects two-stage least squares with standard errors in parentheses, robust to heteroscedasticity and serial correlation, clustered by route-week.

(c) See text for discussion of instruments for Average Price, Price Decrease and interacted terms.

(d) Coefficients $* * *$ statistically significant at $1 \%, * *$ at $5 \%$ and $*$ at $10 \%$. 
Notably, changing the weights of the fare quotes in calculating the average offered price does not affect in any fundamental way the previously reported results for our key variables. Moreover, the effect of Average Price on load factor does not qualitatively change with the weighting system. Replacing Max Price with various versions of Average Price does not alter the conclusion that systematic YM practices are configured as a monotonic relationship linking load factors and offered fares. Furthermore, changing the way we control for systematic pricing does not alter the impact of the YM interventions, which continue to be effective but at a decreasing rate as the share of tourist passenger traffic increases.

Using price range. Table 6 reports the estimation results of our specification, where Max Price is replaced by the variable Max-Min Prices, i.e., the difference between the highest and the lowest price quotes for a given flight on a given date. This provides an alternative way to control for the systematic component of YM. Indeed, airlines usually divide their aircraft into groups of seats, each with a different price which increases as the plane fills up. The variable Max-Min Prices represents the range of the distribution of prices across seats.

We therefore expect a positive sign for the Max-Min Prices coefficient. Since the price range can also be correlated with the error term, we employ the previous instrumental variable approach, and report 2SLS fixed effects results in Table $6{ }^{15}$ Replacing the maximum price with the range of offered fares leaves our key YM-load factor relationship largely intact. As before, our results show that YM interventions are not more effective on more competitive routes. With respect to differences in the effectiveness of YM interventions depending on the share of leisure traffic, specifications (3) and (4) confirm our previously reported result that YM interventions are nearly completely ineffective on the routes where all the passengers are leisure travelers.

\section{Conclusions}

To the best of our knowledge, this paper contributes to the empirical literature on the effectiveness of yield management in the airline industry (Escobari, 2012; Salanti et. al, 2012). We demonstrate that the practice of adjusting fares and seat inventories is effective in increasing the flight load factors; we quantify this effect and determine whether it depends on some broadly defined market characteristics. We combine information on the evolution of offered prices as the flight departure day approaches with the data on final load factors for more than 100,000 unique flights in 100 routes during a 13-months period. A unique feature of our dataset is that it comes from European low-cost carriers. These airlines focus on direct flights, do not incorporate network consideration into their

\footnotetext{
${ }^{15}$ The variable Max-Min Prices is instrumented in the usual fashion, taking the mean of Max-Min Prices for the same flight one and two weeks before and after a given flight's departure.
} 
Table 6: Price range (Max-Min Prices). Dependent variable: Load factor

\begin{tabular}{|c|c|c|c|c|}
\hline & (1) & $(2)$ & $(3)$ & (4) \\
\hline Max-Min Prices & $\begin{array}{c}0.142^{* * *} \\
(0.014)\end{array}$ & $\begin{array}{c}0.132^{* * *} \\
(0.018)\end{array}$ & $\begin{array}{c}0.223^{* * *} \\
(0.068)\end{array}$ & $\begin{array}{c}0.215^{* * *} \\
(0.069)\end{array}$ \\
\hline$($ Max-Min Prices)*(Low Comp.) & & $\begin{array}{c}0.020 \\
(0.028)\end{array}$ & & $\begin{array}{c}0.014 \\
(0.029)\end{array}$ \\
\hline$($ Max-Min Prices $) *($ Tourism $)$ & & & $\begin{array}{c}-0.098 \\
(0.090)\end{array}$ & $\begin{array}{l}-0.097 \\
(0.090)\end{array}$ \\
\hline Price Decrease & $\begin{array}{c}0.262^{* * *} \\
(0.090)\end{array}$ & $\begin{array}{c}0.281^{* * *} \\
(0.104)\end{array}$ & $\begin{array}{c}0.879 * * \\
(0.367)\end{array}$ & $\begin{array}{c}0.906^{* *} \\
(0.370)\end{array}$ \\
\hline (Price Decrease)*(Low Comp.) & & $\begin{array}{c}-0.040 \\
(0.173)\end{array}$ & & $\begin{array}{c}0.084 \\
(0.180)\end{array}$ \\
\hline$($ Price Decrease $) *($ Tourism $)$ & & & $\begin{array}{c}-0.791^{*} \\
(0.465)\end{array}$ & $\begin{array}{l}-0.874^{*} \\
(0.479)\end{array}$ \\
\hline Sundays & $\begin{array}{c}2.705^{* * *} \\
(0.326)\end{array}$ & $\begin{array}{c}2.719^{* * *} \\
(0.334)\end{array}$ & $\begin{array}{c}2.572^{* * *} \\
(0.331)\end{array}$ & $\begin{array}{c}2.553^{* * *} \\
(0.341)\end{array}$ \\
\hline Mondays & $\begin{array}{c}4.273^{* * *} \\
(0.224)\end{array}$ & $\begin{array}{c}4.259^{* * *} \\
(0.223)\end{array}$ & $\begin{array}{c}4.193^{* * *} \\
(0.226)\end{array}$ & $\begin{array}{c}4.184^{* * *} \\
(0.225)\end{array}$ \\
\hline Tuesdays & $\begin{array}{c}0.727^{* * *} * \\
(0.170)\end{array}$ & $\begin{array}{c}0.723^{* * *} \\
(0.170)\end{array}$ & $\begin{array}{c}0.679^{* * *} \\
(0.170)\end{array}$ & $\begin{array}{c}0.688^{* * *} \\
(0.171)\end{array}$ \\
\hline Thursdays & $\begin{array}{c}2.774^{* * *} \\
(0.196)\end{array}$ & $\begin{array}{c}2.766^{* * *} \\
(0.194)\end{array}$ & $\begin{array}{c}2.775^{* * *} \\
(0.198)\end{array}$ & $\begin{array}{c}2.769^{* * *} \\
(0.197)\end{array}$ \\
\hline Fridays & $\begin{array}{c}3.463^{* * *} \\
(0.291)\end{array}$ & $\begin{array}{c}3.464^{* * *} \\
(0.292)\end{array}$ & $\begin{array}{c}3.433^{* * *} \\
(0.293)\end{array}$ & $\begin{array}{c}3.424^{* * *} \\
(0.295)\end{array}$ \\
\hline Saturdays & $\begin{array}{c}2.693^{* * *} \\
(0.315)\end{array}$ & $\begin{array}{c}2.702^{* * *} \\
(0.325)\end{array}$ & $\begin{array}{c}2.712^{* * *} \\
(0.320)\end{array}$ & $\begin{array}{c}2.696^{* * *} \\
(0.329)\end{array}$ \\
\hline Winter Peak (Xmas) & $\begin{array}{c}4.138^{* * *} \\
(0.769)\end{array}$ & $\begin{array}{c}4.117^{* * *} * \\
(0.775)\end{array}$ & $\begin{array}{c}4.360^{* * *} \\
(0.730)\end{array}$ & $\begin{array}{c}4.314^{* * *} \\
(0.737)\end{array}$ \\
\hline Spring Peak (Easter) & $\begin{array}{c}3.322^{* * *} \\
(0.569)\end{array}$ & $\begin{array}{c}3.337^{* * *} \\
(0.588)\end{array}$ & $\begin{array}{c}3.297^{* * *} \\
(0.573)\end{array}$ & $\begin{array}{c}3.235^{* * *} \\
(0.604)\end{array}$ \\
\hline Summer Peak (Mid-August) & $\begin{array}{l}0.915^{*} \\
(0.503)\end{array}$ & $\begin{array}{l}0.913^{*} \\
(0.506)\end{array}$ & $\begin{array}{l}0.960^{*} \\
(0.493)\end{array}$ & $\begin{array}{l}0.888^{*} \\
(0.493)\end{array}$ \\
\hline$R^{2}$ & 0.095 & 0.097 & 0.097 & 0.089 \\
\hline Cragg-Donald $F$-stat & $136.833^{* * *}$ & $46.520^{* * *}$ & $62.003^{* * *}$ & $32.400^{* * *}$ \\
\hline Hansen $\chi^{2}$ & 0.144 & 0.155 & 0.407 & 0.403 \\
\hline Observations & 106,979 & 106,979 & 106,979 & 106,979 \\
\hline
\end{tabular}

(a) Estimation technique: flight-code fixed effects two-stage least squares with standard errors in parentheses, robust to heteroscedasticity and serial correlation, clustered by route-week.

(b) See text for discussion of instruments for Max-Min Price, Price Decrease and interacted terms.

(c) Coefficients *** statistically significant at $1 \%, * *$ at $5 \%$ and $*$ at $10 \%$. 
pricing strategy, sell all their tickets as strictly non-refundable contracts, and do not price discriminate between passengers traveling one-way versus round-trip.

We thus observe price quotes in an environment most closely resembling the theoretical studies of pricing under fixed capacity and uncertain demand. We select the most straightforward indicator of a yield management intervention - the intensity of price drops in fare quotes. A sufficiently high price decrease is a clear indication that demand realization does not proceed as forecast: this represents a situation which is likely to call for the involvement of a yield manager. The reason for picking the most obvious indicator of yield management (instead of evaluating how different the price path for a particular flight is relative to some estimated 'average' pricing profile) is simple. If we fail to observe effectiveness of this technique where it is definitely applied, then we can be quite certain that yield management is not very helpful. If we however see that the yield manager is able to increase the final load factor by decreasing the fare quotes, then this result opens the door to future research on the issue.

We indeed detect that the exercise of 'discretionary' yield management (as defined in our study) by the airlines leads to higher load factors. Specifically, reduction of the offered airfare by one standard deviation raises the flight's load factor on average by 2.7 percent. Yield management does not appear to be more effective on more competitive routes.

Examination of the effectiveness of YM interventions on tourist routes as opposed to markets with more business passengers yields a rather surprising and somewhat counterintuitive result. We determine that YM interventions appear to be nearly completely ineffective on routes with 100 percent leisure traffic. This runs counter to the general perception of leisure passengers being price-sensitive and responsive to price decreases. We attribute our result to the fact that leisure passengers are likely to plan their trips well in advance so that, when an offered price decrease, most leisure passengers have already made their travel arrangements. We believe this question deserves further exploration, which would require more detailed data than what we have employed here.

Yield management is also applicable to and used by railroads, hotels, and rental car companies. The empirical analysis of this phenomenon is lacking: this paper will both help firms apply yield management more effectively and shed light on the extent to which price dispersion in these relevant industries is the result of YM techniques (both systematic and stochastic) or more standard price discrimination. 


\section{References}

[1] Abratea, G., G. Fraquelli, and G. Viglia (2012) "Dynamic pricing strategies: Evidence from European hotels", International Journal of Hospitality Management, 31, 160168.

[2] Alderighi, M., A. Cento, P. Nijkamp, and P. Rietveld (2012) "Competition in the European aviation market: the entry of low-cost airlines", Journal of Transport Geography, 24, 223233.

[3] Bachis, E., and C. A. Piga (2011) "Low-Cost Airlines and online Price Dispersion", International Journal of Industrial Organization. 26(6), 655-677.

[4] Balaguer, J., and J. C. Pernías (2013) "Relationship between spatial agglomeration and hotel prices. Evidence from business and tourism consumers", Tourism Management, 36, 391-400.

[5] Becerra, M., J. Santaló, and R. Silva (2013) "Being better vs. being different: Differentiation, competition, and pricing strategies in the Spanish hotel industry", Tourism Management, 34, 71-79.

[6] Borenstein, S. and N. Rose (1994) "Competition and Price Dispersion in the U.S. Airline Industry", Journal of Political Economy, 102(4), 653-683.

[7] Clark, R. and N. Vincent (2012) "Capacity-contingent pricing and competition in the airline industry", Journal of Air Transport Management, 24, 7-11.

[8] Cragg, J. and S. Donald (1993) "Testing Identifiability and Specification in Instrumental Variable Models", Econometric Theory, 9, 222-240.

[9] Dana, J. (1999a) "Equilibrium Price Dispersion Under Demand Uncertainty: the Roles of Costly Capacity and Market Structure", RAND Journal of Economics, 30(3), 632-660.

[10] Dana, J. (1999b) "Using yield management to shift demand when peak time is unknown", RAND Journal of Economics, 30(4), 456-474.

[11] Deneckere, R. and J. Peck (2012) "Dynamic Competition With Random Demand and Costless Search: A Theory of Price Posting", Econometrica, 3, 1185-1247.

[12] Dobson, P. and C. Piga (2013) "The Impact of Mergers on Fares Structure: Evidence from European Low-Cost Airlines", Economic Inquiry, 51(2), 1196-1217.

[13] Escobari D. (2012) "Dynamic Pricing, Advance Sales, and Aggregate Demand Learning in Airlines", Journal of Industrial Economics, 60(4), 697-724. 
[14] Escobari, D. and L. Gan (2007) "Price Dispersion under Costly Capacity and Demand Uncertainty", NBER working paper 13075.

[15] European Commission (2007) "Case No COMP/M. 4439 - Ryanair / Aer Lingus", downloadable at http://ec.europa.eu/competition/mergers/cases/decisions/ m4439_20070627_20610_en.pdf.

[16] Gaggero, A. and C. Piga (2011) "Airline Market Power and Intertemporal Price Dispersion", Journal of Industrial Economics, 59(4), 552-577.

[17] Gale, I. and T. Holmes (1992) "The Efficiency of Advance-Purchase Discounts in the Presence of Aggregate Demand Uncertainty", International Journal of Industrial Organization, 10, 413-437.

[18] Gale, I. and T. Holmes (1993) "Advance-Purchase Discounts and Monopoly Allocation of Capacity", American Economic Review, 83, 135-146.

[19] Gerardi, K. and A. Shapiro (2009) "Does Competition Reduce Price Dispersion? New Evidence from the Airline Industry", Journal of Political Economy, 117, 1-37.

[20] Gershkov, A. and Moldovanu, B (2012) "Dynamic Allocation and Pricing: A Mechanism Design Approach", International Journal of Industrial Organisation, 30(3), 283-286.

[21] Hausman, J. (1978) "Specification Tests in Econometrics", Econometrica, 46(6), $1251-1271$.

[22] Hayes, K. and L. Ross (1998) "Is Airline Price Dispersion the Result of Careful Planning or Competitive Forces?", Review of Industrial Organization, 13, 523-541.

[23] Hernandez, M. and S. Wiggins (2009) "Nonlinear Pricing Strategies and Market Concentration in the Airline Industry", mimeo.

[24] Malighetti, P., S. Paleari, and R. Redondi (2010) "Has Ryanair's pricing strategy changed over time? An empirical analysis of its 2006-2007 flights", Tourism Management, 31, 36-44.

[25] McAfee, P. and te Velde, V. (2007): "Dynamic Pricing in the Airline Industry", in Handbook on Economics and Information Systems, Vol. 1, Ed. T.J. Hendershott, Elsevier Handbooks in Information Systems I, New York.

[26] McGill, J. and G. Van Ryzin (1999) "Revenue Management: Research Overview and Prospects", Transportation Science, 33(2), 233-256.

[27] Möller, M. and M. Watanabe (2010) "Advance Purchase Discounts versus Clearance Sales", Economic Journal, 120, 1125-1148. 
[28] Puller, S., A. Sengupta, and S. Wiggins (2009) "Testing Theories of Price Dispersion and Scarcity Pricing in the Airline Industry", NBER working paper 15555.

[29] Puller, S. and L. Taylor (2012) "Price discrimination by day-of-week of purchase: Evidence from the U.S. airline industry", Journal of Economic Behavior \& Organization, vol. 84(3), 801-812.

[30] Salanti A., P. Malighetti, and R. Redondi (2012) "Low-cost pricing strategies in leisure markets", Tourism Management, 33, 249-256.

[31] Stavins, J. (2001) "Price Discrimination in the Airline Market: The Effect of Market Concentration", Review of Economics and Statistics, 83, 200-202.

[32] Stock, J. and M. Yogo (2005) "Testing for Weak Instruments in Linear IV Regression" in Andrews, D. and Stock, J. (eds.), Identification and Inference for Econometric Models: Essays in Honor of Thomas Rothenberg, pp. 80-108 (Cambridge University Press, Cambridge, England).

[33] Weatherford L. and S. Bodily (1992) "A Taxonomy and Research Overview of Perishable-Asset Revenue Management: Yield Management, Overbooking, and Pricing", Operations Research, 5, 831-844. 


\section{Appendix}

Table 7: First-stage estimates

\begin{tabular}{|c|c|c|c|c|}
\hline Dependent Variable & $\begin{array}{c}\text { (1) } \\
\text { Max Price }\end{array}$ & $\begin{array}{c}(2) \\
\text { Price Decrease }\end{array}$ & $\begin{array}{c}(3) \\
\text { Max Price }\end{array}$ & $\begin{array}{c}(4) \\
\text { Price Decrease }\end{array}$ \\
\hline Lags-Leads Max Price & $\begin{array}{c}0.456^{* * *} \\
(0.015)\end{array}$ & $\begin{array}{c}0.027^{* * *} \\
(0.003)\end{array}$ & $\begin{array}{c}0.718^{* * *} \\
(0.057)\end{array}$ & $\begin{array}{l}-0.015 \\
(0.014)\end{array}$ \\
\hline Lags-Leads Price Decrease & $\begin{array}{c}-0.086^{* * * *} \\
(0.019)\end{array}$ & $\begin{array}{c}0.082^{* * *} \\
(0.010)\end{array}$ & $\begin{array}{c}-0.195^{* *} \\
(0.084)\end{array}$ & $\begin{array}{c}0.203^{* * *} \\
(0.046)\end{array}$ \\
\hline Holiday period & $\begin{array}{c}-2.552^{* * *} \\
(0.320)\end{array}$ & $\begin{array}{c}-0.639^{* * *} \\
(0.125)\end{array}$ & $\begin{array}{c}-2.553^{* * *} \\
(0.319)\end{array}$ & $\begin{array}{c}-0.634^{* * *} \\
(0.125)\end{array}$ \\
\hline (Lags-Leads Max Price)*(Low Comp) & & & $\begin{array}{c}-0.098^{* * *} \\
(0.027)\end{array}$ & $\begin{array}{l}-0.003 \\
(0.006)\end{array}$ \\
\hline${\text { (Lags-Leads Max Price })^{*}(\text { Tourism) }}$ & & & $\begin{array}{c}-0.259^{* * *} \\
(0.068)\end{array}$ & $\begin{array}{c}0.053^{* * *} \\
(0.017)\end{array}$ \\
\hline (Lags-Leads Price Decrease) ${ }^{*}($ Low Comp) & & & $\begin{array}{c}0.084^{* *} \\
(0.038)\end{array}$ & $\begin{array}{c}-0.044^{* *} \\
(0.020)\end{array}$ \\
\hline (Lags-Leads Price Decrease)*(Tourism) & & & $\begin{array}{c}0.073 \\
(0.105)\end{array}$ & $\begin{array}{c}-0.120^{* *} \\
(0.057)\end{array}$ \\
\hline Sundays & $\begin{array}{c}13.263^{* * *} \\
(0.501)\end{array}$ & $\begin{array}{c}1.926^{* * *} \\
(0.194)\end{array}$ & $\begin{array}{c}13.010^{* * *} \\
(0.503)\end{array}$ & $\begin{array}{c}1.954^{* * *} \\
(0.194)\end{array}$ \\
\hline Mondays & $\begin{array}{c}7.059^{* * *} \\
(0.385)\end{array}$ & $\begin{array}{l}0.280^{*} \\
(0.156)\end{array}$ & $\begin{array}{c}6.988^{* * * *} \\
(0.384)\end{array}$ & $\begin{array}{l}0.296^{*} \\
(0.156)\end{array}$ \\
\hline Tuesdays & $\begin{array}{l}-0.370 \\
(0.297)\end{array}$ & $\begin{array}{l}-0.141 \\
(0.133)\end{array}$ & $\begin{array}{l}-0.370 \\
(0.297)\end{array}$ & $\begin{array}{l}-0.149 \\
(0.134)\end{array}$ \\
\hline Thursdays & $\begin{array}{c}4.477^{* * *} \\
(0.275)\end{array}$ & $\begin{array}{c}0.727^{* * *} \\
(0.130)\end{array}$ & $\begin{array}{c}4.463^{* * *} \\
(0.274)\end{array}$ & $\begin{array}{c}0.731^{* * *} \\
(0.130)\end{array}$ \\
\hline Fridays & $\begin{array}{c}11.041^{* * *} \\
(0.411)\end{array}$ & $\begin{array}{c}1.294^{* * *} \\
(0.165)\end{array}$ & $\begin{array}{c}10.902^{* * *} \\
(0.412)\end{array}$ & $\begin{array}{c}1.314^{* * *} \\
(0.165)\end{array}$ \\
\hline Saturdays & $\begin{array}{c}8.518^{* * * *} \\
(0.394)\end{array}$ & $\begin{array}{c}2.100^{* * *} \\
(0.168)\end{array}$ & $\begin{array}{c}8.487^{* * *} \\
(0.394)\end{array}$ & $\begin{array}{c}2.112^{* * *} \\
(0.168)\end{array}$ \\
\hline Winter Peak (Xmas) & $\begin{array}{c}32.231^{* * *} \\
(1.574)\end{array}$ & $\begin{array}{c}5.676^{* * *} \\
(0.489)\end{array}$ & $\begin{array}{c}32.294^{* * *} \\
(1.575)\end{array}$ & $\begin{array}{c}5.680^{* * * *} \\
(0.488)\end{array}$ \\
\hline Spring Peak (Easter) & $\begin{array}{c}14.385^{* * *} \\
(1.177)\end{array}$ & $\begin{array}{c}2.819^{* * *} \\
(0.407)\end{array}$ & $\begin{array}{c}14.325^{* * *} \\
(1.174)\end{array}$ & $\begin{array}{c}2.828^{* * *} \\
(0.407)\end{array}$ \\
\hline Summer Peak (Mid-August) & $\begin{array}{c}-6.589^{* * *} \\
(1.345)\end{array}$ & $\begin{array}{l}-1.270 \\
(0.835)\end{array}$ & $\begin{array}{c}-6.499^{* * *} \\
(1.361)\end{array}$ & $\begin{array}{l}-1.299 \\
(0.832)\end{array}$ \\
\hline$R^{2}$ & 0.197 & 0.023 & 0.199 & 0.024 \\
\hline Observations & 106,979 & 106,979 & 106,979 & 106,979 \\
\hline
\end{tabular}

(a) Columns (1) and (2) are first-stage estimates of Model (2) in table 3; Columns (3) and (4) are first-stage estimates of Model (3) in table 4.

(b) The regressions include flight-code fixed effects. Robust standard errors to heteroscedasticity and serial correlation in parentheses, clustered by route-week.

(c) Coefficients $* * *$ statistically significant at $1 \%$, ** at $5 \%$ and $*$ at $10 \%$. 